\section{Retroactive inhibition of preexperimentally established associations through 24 hours*}

\author{
ERIC P. RUSSELL and ALBERT E. GOSS \\ New Jersey Regional Drug Abuse Agency, Jersey City \\ and \\ Douglass College, Rutgers-The State University, New Brunswick, N.J. 08903
}

In replication and extension of a prior experiment, both male and female undergraduates provided " $B$ " associations to " $A$ " words with primaries of high and low-frequency by Palermo and Jenkins's norms. This $A B$ pretest was followed by 10 trials of acquisition of $\mathrm{AC}$ or $\mathrm{DC}$ associations. In an $\mathrm{AB}$ posttest with $\mathrm{A}$ words again alone, more $\mathrm{C}$ words and fewer pretest-posttest agreements of $B$ responses occurred after acquisition of $A C$ than of $D C$ associations. These differences obtained in two trials immediately after acquisition and in a third trial that was administered either immediately or $24 \mathrm{~h}$ after the first two trials. $\mathrm{RI}$ of preexperimentally established associations extends through $24 \mathrm{~h}$.

Russell \& Goss (1969) describe experimental induction of retroactive inhibition (RI) of preexperimentally acquired or "natural language" relationships between words and their associates. In $A B, A C, A B$ experimental and $\mathrm{AB}, \mathrm{DC}, \mathrm{AB}$ control conditions, AB represented preexperimentally established relationships between words and distributions of associates. These distributions were characterized by high-frequency primaries (high-f) and relatively few different responses or by low-frequency primaries (low-f) and relatively many different responses. The word-associate relationships were inferred indirectly from Palermo \& Jenkins's (P-J, 1964) norms. They were determined directly by assessment before (pretest) and after (posttest) acquisition of $\mathrm{AC}$ or $\mathrm{DC}$ associations. In the $A B$ posttest, fewer $A B$ associations and more AC associations followed acquisition of $\mathrm{AC}$ than of $\mathrm{DC}$ associations. However, RI of the $A B$ associations did not differ between words with high-f or low-f primaries.

The present experiment replicates and extends the original experiment. The Ss of the original experiment were all male; the Ss of the present experiment are equally males and females. The two $\mathrm{AB}$ posttest trials of the original experiment are extended to a third trial that occurred either immediately or $24 \mathrm{~h}$ later. The concern was whether or not RI extends through $24 \mathrm{~h}$.

\footnotetext{
*This experiment is part of a subprogram of research within a program of research on transfer of response hierarchies that is supported by Grant MH 13531 . Donald J. supported by Grant $\mathrm{MH} 13531$. Donald Juliette $M$. Anable and Ilona $K$. Merel aided in data reduction.
}

instructions by tape playback from their recording by $\mathrm{E}$ rather than by his reading them directly; and (2) the third posttest retention trial either immediately or $24 \mathrm{~h}$ later.

\section{SUBJECTS}

Forty male and 40 female undergraduates were chosen from courses in introductory psychology at Rutgers College and Douglass College, respectively. They were assigned randomly in equal numbers to each of the four combinations of $\mathrm{AC}$ or $\mathrm{DC}$ tasks and immediate or 24-h interval, and were run in groups.

\section{RESULTS}

AB Pretest

For each A word, Table 1 shows the primary response(s), its (their) frequency (f), and number of different responses (N) for $\mathrm{Ss}$ preassigned to $\mathrm{AC}$ or DC list. Distributions of associations of males and females within these conditions overlap. The primaries of boy, lamp, and dogs are those of the P.J norms. They are also those of the original experiment except that, for the AC condition, "shade" did not recur as a primary of lamp.

The primaries of citizen, people, and soldier are among primaries or associations of the P-J norms. The primaries for "citizen" for the DC condition, for "people" for the AC condition, and for "soldier" for both $A C$ and $D C$ conditions are the same as or among primaries of these words in conditions of the original experiment.

In agreement with P-J norms and with constants of distributions of the original experiment, boy, lamp, and dogs had high-f primaries and relatively few different responses, and citizen, people, and soldier had low-f primaries and relatively many different responses. With the exception of frequency of light to lamp for $\mathrm{DC}$, these frequencies of primaries and numbers of different responses do not overlap.

Table 1

Primary Response(s), Its Frequency (f), and Number of Different Responses (N) to Each Word With P.J Primaries of High $f$ and Low $f$ During the AB Pretest for Ss Preassigned to the AC or DC List

\begin{tabular}{|c|c|c|c|c|c|}
\hline$P \cdot J$ & Word & List & Primary & f & $\mathbf{N}$ \\
\hline \multirow{6}{*}{ High } & \multirow{2}{*}{ Boy } & $\mathrm{AC}$ & Girl* & 35 & 6 \\
\hline & & DC & Girl & 36 & 4 \\
\hline & \multirow{2}{*}{ Lamp } & $\mathrm{AC}$ & Light* & 16 & 8 \\
\hline & & DC & Light & 24 & 6 \\
\hline & \multirow{2}{*}{ Dogs } & $\mathrm{AC}$ & Cats* & 32 & 7 \\
\hline & & $\mathrm{DC}$ & Cats & 33 & 7 \\
\hline \multirow{7}{*}{ Low } & \multirow{2}{*}{ Citizen } & $\mathrm{AC}$ & Country $\dagger$ & 8 & 20 \\
\hline & & DC & Country & 12 & 20 \\
\hline & \multirow{3}{*}{ People } & $\mathrm{AC}$ & Crowd(s)* & 6 & 23 \\
\hline & & DC & Placest & 4 & 25 \\
\hline & & & Man, Ment & 4 & \\
\hline & \multirow{2}{*}{ Soldier } & $\mathrm{AC}$ & Wart & 11 & 13 \\
\hline & & DC & War & 17 & 12 \\
\hline
\end{tabular}

*Agrees with $P J$ primary; tamong $P \cdot J$ associations 
Table 2

Mean Correct Responses Per Pair for All 10 Trials of Acquisition (Acq) of AC or DC Lists, and Mean Frequencies of $C$ Responses and of Agreements (Agrmnt) Per Pair During the AB Posttest for List, Interval, and $f$ of Primary

\begin{tabular}{|c|c|c|c|c|}
\hline Interval & f & Acq & C & Agrmnt \\
\hline \multicolumn{5}{|c|}{ CA List } \\
\hline $\begin{array}{l}\text { Immediate } \\
24 \mathrm{~h}\end{array}$ & $\begin{array}{l}\text { High } \\
\text { Low } \\
\text { High } \\
\text { Low }\end{array}$ & $\begin{array}{l}8.8 \\
7.3 \\
8.1 \\
6.8\end{array}$ & $\begin{array}{l}6.2 \\
2.6 \\
6.1 \\
3.2\end{array}$ & $\begin{array}{r}10.1 \\
7.1 \\
10.2 \\
7.9\end{array}$ \\
\hline \multicolumn{5}{|c|}{ DC List } \\
\hline $\begin{array}{l}\text { Immediate } \\
24 \mathrm{~h}\end{array}$ & $\begin{array}{l}\text { High } \\
\text { Low } \\
\text { High } \\
\text { Low }\end{array}$ & $\begin{array}{l}8.9 \\
6.9 \\
9.1 \\
6.8\end{array}$ & $\begin{array}{l}0.0 \\
0.0 \\
0.0 \\
0.0\end{array}$ & $\begin{array}{r}14.5 \\
9.3 \\
14.6 \\
9.9\end{array}$ \\
\hline
\end{tabular}

AC, DC Acquisition

Table 2 shows mean correct responses per pair through all 10 trials for words in AC or DC lists with high-f or low-f primaries in lists for $\mathrm{Ss}$ preassigned to an immediate or 24 -h interval. By Trial 10, 25 Ss were responding perfectly on the $A C$ list and 26 Ss on the DC list. For both lists, most errors were omissions.

The variables of the analysis of variance were lists, sex, interval, $f$ of primaries, individual $A$ words nested in primaries, and trials.

Across other varibles, $\mathrm{AC}(\overline{\mathrm{X}}=7.7)$ and $\mathrm{DC}(\overline{\mathrm{X}}=7.9)$ lists were equivalent, $F(1,72)=0.39, p=.65$. Across other variables, $\mathbf{C}$ words assigned to $\mathbf{A}$ words with high-f primaries and to $D$ words $(\bar{X}=8.7)$ were learned more rapidly than $C$ words assigned to $A$ words with low-f primaries and to $D$ words $(\bar{X}=6.9), F(1,72)=137.78, p<.01$. Because this difference held for both $A C$ and DC lists, it simply indicates that high-f $C$ words are easier to acquire than low-f $\mathrm{C}$ words.

Preassignment to retention interval made no difference, $F(1,72)=1.31$, $p=.40$. Acquisition was faster for women $(\bar{X}=8.4)$ than for men $(\bar{X}=7.3), \quad F(1,72)=15.91, \quad p<.01$ but sex had no other differential importance. Bases of differences among individual $A$ words nested in high-f or low-f primaries, $F(4,288)=37.12, p<.01$, are not identifiable.

\section{AB Posttest}

Responses to $A$ in the $A B$ posttest may be examined for carryover of $C$ responses from acquisition of the $\mathrm{AC}$ list, and for agreement (or difference) between pretest and posttest $B$ responses. In the original experiment, the latter measure was difference or change. Complementary occurrence of more frequent $\mathrm{C}$ responses and of less frequent agreements for the $\mathrm{AC}$ than for the $D C$ condition indicates $R I$ of pretest $A B$ relationships.

$C$ responses. For comparison with pretest frequencies, Table 2 also shows mean frequency of $\mathrm{C}$ responses per word per trial for lists. Frequency of $\mathrm{C}$ responses on each trial is not shown; frequency of $\mathrm{C}$ responses did not differ among trials, $F(2,144)=2.43$, $\mathrm{p}>.05$.

With the $\mathrm{AC}$ list, $\mathrm{C}$ responses decreased between the first and second posttest trial. Whether or not the third trial occurred immediately or after $24 \mathrm{~h}$, they did not change between the second and third posttest trial. With the DC list, there were no differences among trials. Lists and trials interact, $F(2,144)=3.13, p<.05$, but they do not interact with retention interval, $F(2,144)=2.90, p>.05$.

$C$ responses carried over from acquisition of AC. One $S$ who responded twice with a $C$ response excepted, $C$ responses did not occur after acquisition of DC, $F(1,72)=25.74, p<.01$. Within the $A C$ list, twice as many $C$ responses occurred to $A$ words with high-f than to those with low-f primaries, $F(1,72)=23.58, p<.01$. Because this difference was confined to the AC list, lists interacted with $f$ of primary, $F(1,72)=26.95, p<.01$. These two variables together did not interact with retention interval or with any other variable(s).

Differences occurred among words nested in f of primary, $F(4,288)=3.90, \quad p<.01$. These differences are of no interpretative consequence. Sex made no difference.

Agreements. Table 2 also shows mean frequency of pretest-posttest agreements of $B$ response per word per trial. Across AC and DC lists, frequency of agreements did not differ among trials, $F(2,144)=2.93, p>.05$. With the AC list, agreements did not differ among trials. With the DC list, they changed between the first and second and between the second and third posttest trials. The latter decrease was half the former decrease. Lists and trials interact, $F(\dot{2}, 144)=6.01, p<.01$, but not with retention interval, $F(2,144)=1.04$, $\mathrm{p}=.50$.

Fewer agreements occurred after acquisition of AC than of DC lists, both across combinations of $f$ of primary and retention interval, $F(1,72)=9.34, p<.01$, and at each level of $f$ of primary and interval, separately and combined.

Within AC and DC lists both across and at each retention interval, more agreements occurred for words with high- $f$ than with low-f primaries, $F(1,72)=36.50, \quad p<.01$. Although the difference between high-f and low-f primaries was less for the $A C$ than for the $D C$ list, $F(1,72)=4.28$, $\mathrm{p}<.05$, these variables together do not interact with retention interval or any other variable(s). The differences among words nested in $\mathrm{f}$ of primary, $F(4,288)=2.55, p<.05$, are of no interpretive consequence. Sex made no difference.

\section{DISCUSSION}

AB Pretest

Primaries of associations to $A$ words compare reasonably with primaries and other association of the P-J norms (Palermo \& Jenkins, 1964) and agree well with those obtained in the original experiment. With allowance for difference in numbers of Ss, frequencies of primaries and number of different associations are also consistent with values for these descriptive constants in the P-J norms and in the original experiment.

AB Posttest

No apparent pretest differences held between AC and DC conditions, between Ss preassigned to the immediate or 24-h interval for the third AB posttest trial, or among combinations of lists and intervals. Acquisition was equivalent for $\mathrm{AC}$ and DC lists. Therefore, posttest differences between $A C$ and $D C$ lists are not likely to reflect pretest differences or differences in rate of acquisition of $\mathrm{AC}$ or $\mathrm{DC}$ associations.

During the first two AB pósttest trials, across words with high-f and low-f primaries, more $C$ responses and fewer pretest-posttest agreements occurred after acquisition of the AC list than of the DC list. These differences replicate thase obtained in the original experiment. These differences also held during the third posttest trial both immediately and $24 \mathrm{~h}$ later. RI of preexperimentally established associations extends over $24 \mathrm{~h}$.

For comparable conditions, means of frequencies of $C$ responses and patterns of changes in $B$ responses in the original experiment and of agreements in this experiment are consistent. Results of both experiments indicate that stable preexperimentally established or natural $A B$ associations are modified by acquisition of interfering responses within a laboratory context.

Whether or not RI differed between words with high- $f$ and low- $f$ primaries is ambiguous. With the AC list, more $\mathrm{C}$ responses occurred to words with high-f than to those with low-f primaries. With the AC list, agreement was greater for words with high-f than for those with low-f primaries. This difference was less for the AC than for the DC list which, in conjunction with fewer agreements with the AC than the DC list, suggests interference from acquisition of $A C$ associations. However, $C$ responses to words with high-f primaries were easier to acquire than were $C$ responses to words with low-f primaries. Posttest differences 
may simply reflect differences during acquisition of $\mathrm{AC}$ associations. For reasons too complex to present here, covariance adjustment of posttest $C$ responses and agreements did not seem warranted.

Following acquisition of the $\mathrm{AC}$ list, $C$ responses to words with high-f and low-f primaries were less frequent than they had been across all 10 or during the last of the acquisition trials. These decrements presumably reflect change in instructions and consequent set, and in context of $\mathrm{A}$ words. Nonetheless, $\mathrm{C}$ responses continued to occur: responses acquired in a paragraph or discourse layout transfer to a word-association situation or task.

\section{REFERENCES}

PALERMO, D. S., \& JENKINS, J. J. Word association norms. Minneapolis: University of Minnesota Press, 1964.

RUSSELL, E. P., \& GOSS, A. E Retroactive inhibition of preexperimentally established associations. Psychonomic Science, 1969. $14,173-174$. meaningfulness and IQ upon the slope of the delay gradients in a successive discrimination learning task with retardates. It was hypothesized that meaningful materials (pictures of common objects) would provide mediating responses (labeling) more readily than would nonmeaningful stimuli. Similarly, more intelligent Ss should be better able to produce mediating responses and therefore show relatively less decrement with increasing delays than would less intelligent Ss. The latter prediction is also derivable from Ellis's (1963) hypothesis that the rate of decay of a stimulus trace is a function of intelligence.

\section{SUBJECTS}

The Ss were 45 mentally retarded females selected from the population of the Partlow State School in Tuscaloosa, Alabama. Of these Ss, 9 were discarded: 3 for failure to follow instructions, 3 for alternation of perseveration, 2 for fixation of the incorrect response (18 consecutive incorrect responses to a given stimulus), and 1 due to an equipment failure. The remaining 36 comprised two intelligence groups: 18 borderline and 18 mildly retarded individuals (classified according to Heber, 1961). The borderline retardation group had a mean IQ of 74.5 (range- 70 to 83 ) and a mean $C A$ of 24 years 5 months (range-13:3 to 40:2). The mildly retarded group had a mean IQ of 61.3 (range -55 to 67 ) and a mean $\mathrm{CA}$ of 28 years 3 months (range-17:8 to 46:1).

\section{APPARATUS}

A response console, a Kodak Carousel projector, and programming equipment comprised the apparatus. The response console consisted of a left and right response lever mounted approximately $10 \mathrm{~cm}$ apart on a metal casing. It was located on a table in the experimental room. Behind the table and mounted in the wall was a 20-cm-square rear projection screen. The screen was directly in front of $S$ at about eye level when seated. A room adjacent to the experimental room housed the projector and all programming equipment. The programming equipment controlled timing of the intervals, action of the projector, and a feedback to the S. All operations were automatically controlled except that $E$ set manually the delay interval for each trial.

$$
\text { PROCEDURE }
$$

Each $\mathbf{S}$ performed on a successive discrimination task. He was required to learn a left or right response to each of six stimuli, three meaningful and three nonmeaningful. The meaningful stimuli were pictures of a dog, an Indian, and a group of flowers. The nonmeaningful stimuli were nonsense 